\title{
Stand testing of energy saving motor oil in the internal combustion engine
}

\author{
Anatoliy Ponomarenko ${ }^{1, *}$, Vitaliy Dudnik ${ }^{2}$, Nadiia Afanasieva ${ }^{2}$, Mikhail Boiko $^{3}$ \\ ${ }^{1}$ SFEDU, 344006, Rostov-on-Don, st. B. Sadovaja, 105/42, Russia \\ ${ }^{2}$ DonSTU, 344000, Rostov-on-Don, sq. Gagarina, 1, Russia \\ ${ }^{3}$ Don-Invec LTD, 344090, Rostov-on-Don, av. Stachki, 194/2, Russia
}

\begin{abstract}
The problem of increasing the power efficiency of internal combustion engines by the method of its tribochemical treatment was considered. Concentrate additives Komol on the base of molybdenum complexes was developed. This concentrate reduces fuel consumption and increases engine power. In this paper the Subaru EJ-25 engine used in aviation and automotive industry was investigated before and after the tribochemical treatment by the bench tests. It's shown that adding tribochemically active additives into motor oil increases maximal engine power to $10,7 \%$ which is $8,7 \%$ on comparable engine rotation speeds. The effect was caused by reduced frictional losses as a result of the tribopolymer films formed on friction surfaces.
\end{abstract}

\section{Introduction}

Nowadays four-stroke piston internal combustion engines (ICE) are often used for general aviation. The ICE operation is followed by a great heat generation due to high temperatures of the burnt gases and contact stresses in the engine friction pairs. Therefore, the parts that form friction pairs are lubricated and cooled down. The quality of the motor oil impacts the engine power efficiency, especially its lifetime, wear resistance and friction energy losses.

One of the most successful ways to prevent the wear of engine moving parts, such as pistons and cylinders, is the use of tribochemical additives. Tribochemical reactions during the engine operation lead to the formation of films with a thickness of some tens and hundreds nanometers. The tribochemical films protect the covered surface from wear and degradation. Modern lubrication systems use oils that contain chemical additions of different composition.

In recent years the active compounds of lubricating oil additives include such elements as sulfur [1] and phosphorus [2] which improve antifriction, antiwear and other characteristics. In the case of additives that contain several active compounds, the zinc dialkyldithiophosphate is most widely used [3]. Our previous studies of tribochemical processes on friction surfaces have demonstrated that under certain conditions these surfaces get covered with polymer film capable of reducing the friction coefficient up to 10 times [4]. The bench tests show that the significant decrease in friction losses lowers the fuel consumption of ICE by up to $10 \%$ and increases its capacity [5].
Traditionally, oils modified by tribochemical additives (energy-saving oils) include coordination compounds of transition metals and complex esters of organic acids, which participate in tribochemical processes of forming a tribopolymer film.

The results of comparative tribometric tests of additive concentrates with coordination compounds of different transition metals in SAE10W40 motor oil are shown in Table 1.

Table 1. The results of tribometric tests of SAE10W40 oil with concentrates of additives of transition metals in an amount of $2 \%$ using end friction machine.

\begin{tabular}{|c|c|c|}
\hline $\begin{array}{c}\text { Metal in coordination } \\
\text { compound of additive }\end{array}$ & $\begin{array}{c}\text { Friction } \\
\text { coefficient }\end{array}$ & $\begin{array}{c}\text { Load capacity, } \\
\text { MPa }\end{array}$ \\
\hline- & 0,083 & 68 \\
\hline copper & 0,011 & 153 \\
\hline nickel & 0,014 & 138 \\
\hline cobalt & 0,018 & 136 \\
\hline zinc & 0,017 & 134 \\
\hline molybdenum & 0,010 & 158 \\
\hline
\end{tabular}

The results demonstrate that injected additives reduce the value of friction coefficient by the rate of 4,9-8,3. Additionally, load capacity increases by the rate of 2,02,3 in comparison to initial motor oil. This effect can be explained by the tribopolymer film formed on friction surfaces (Fig. 1 b, c). The film eliminates direct contact of metal surfaces and replaces it with friction between two polymers, which in the presence of oil reduces the value of friction coefficient significantly. The presence of tribopolymer film on conjugated surfaces considerably increases the real area of contact and thus the load capacity rises.

\footnotetext{
* Corresponding author: invec@mail.ru
} 


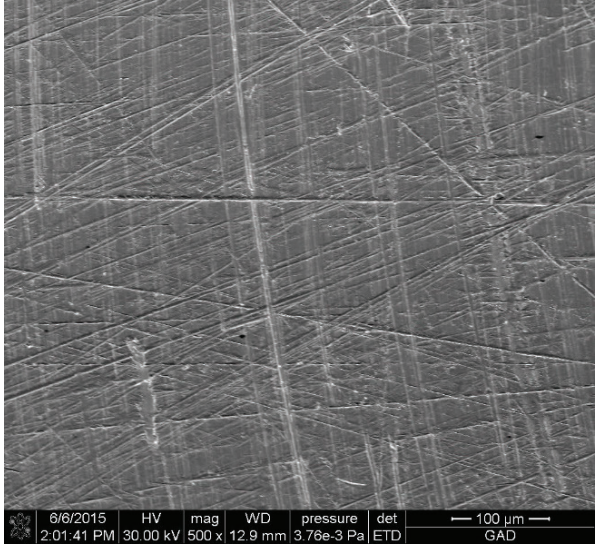

(a)

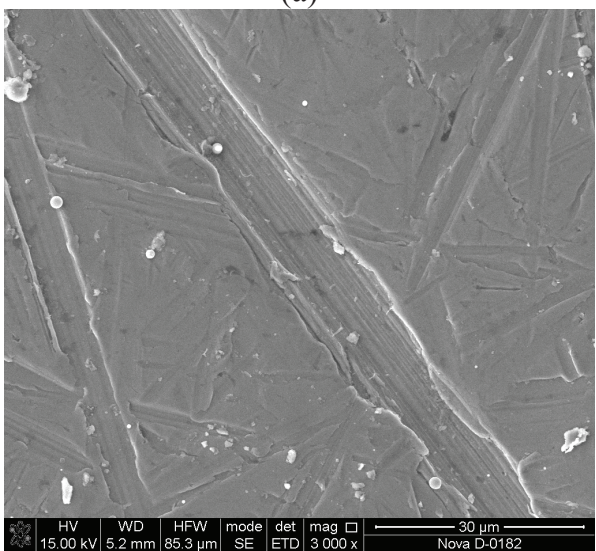

(b)

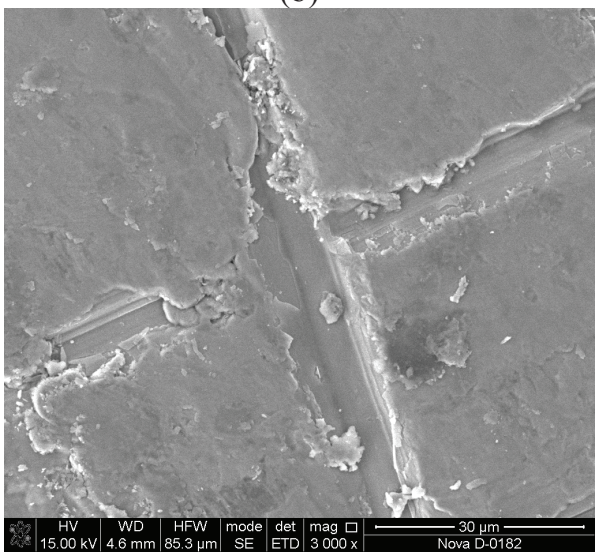

(c)

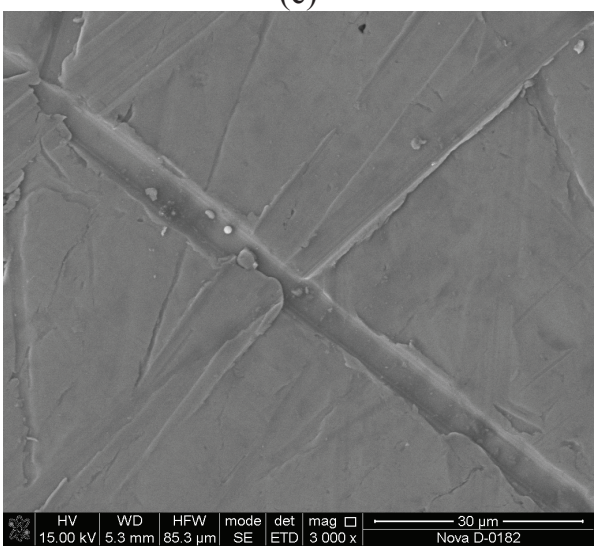

(d)

Fig. 1. SEM picture of surface (a) after the friction test in initial oil; in modified oil with (b) copper complex, (c) nickel complex, (d) molybdenum complex.
Field tests of SAE5W30 motor oil intended for ICE used in passenger cars were conducted. The oil composition was enriched with oil-soluble coordination compound of molybdenum in the form of additives concentrate Komol. The surface pictures taken after the friction test in initial oil (Fig. 1a) and in modified oil (Fig. 1 (b-d)) are presented in Fig. 1.

The bench tests of effects caused by motor oil modification were performed on an engine unit based on the Subaru EJ-25 conversion engine. The tested engine was taken from the aircraft "Shmel" produced in Russia (fig. 2) after 410 flight hours on board. The Subaru EJ25 conversion engines are used in the automotive industry and can be transformed for aviation by replacing the control and transmission units. These engines are applied on a number of aircrafts and helicopters, such as Dinali H2S, Cikwere CH-12, AeroCopter AK1-3 and others.

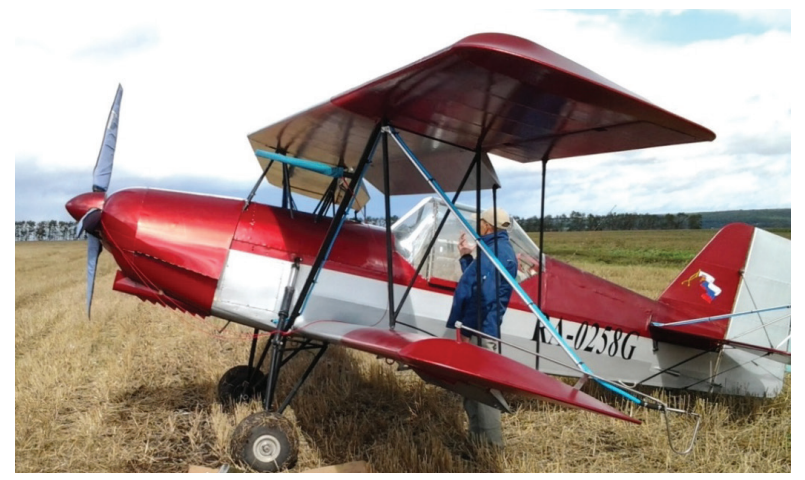

Fig. 2. The aircraft "Shmel" whose engine was used for motor oil modification bench tests (Source: Author's own figure).

\section{Measuring equipment}

The measurements of engine unit parameters after the motor oil modification were performed by using the specially developed test bench capable of imitating the activity of aircraft engine at the starting. The test bench (Fig. 3a) includes: the metal frame, fuel tank, engine support, the engine itself, cooling system and the measurements panel that includes a set of devices for measuring the standard engine parameters.

The propeller with variable blade step was used as loading device. Engine load was controlled by the way of blades pitch angle variation. The intermediate shaft with two flanges was installed between propeller and the engine reduction gear.

Propeller power consumption measurements were based on intermediate shaft deformation. The measurements were performed by using the four tensometers glued to the shaft at an angle of $45^{\circ}$ to each other and with the bridge switching circuit. The usage of bridge circuit reduces the influence of temperature on the measurement results. The data from the tensometers were received by a small-size radio transmitter installed directly on the rotating shaft. The transmitter was controlled by using a serial peripheral interface (SPI) that synchronizes any transmission with common clock signal generated by processor. 
The torque meter installed on the intermediate shaft of tested engine is shown in fig. 3b. The battery was installed opposite to the transmitter in order to provide mass balance. The tensometers were installed in the middle of intermediate shaft and thus the shaft did not change in thickness and shape at the distance of $40 \mathrm{~mm}$ before and after that.

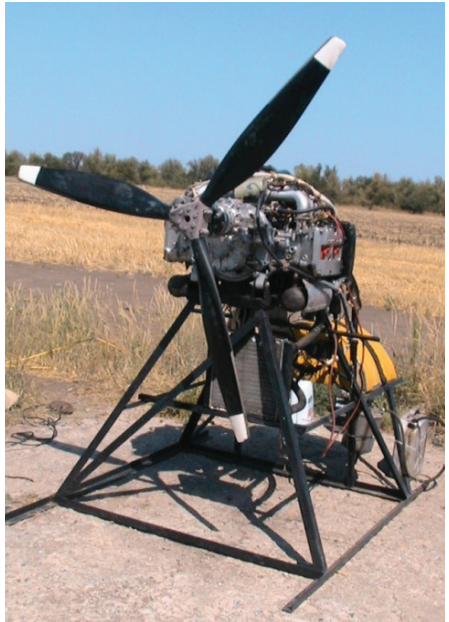

(a)

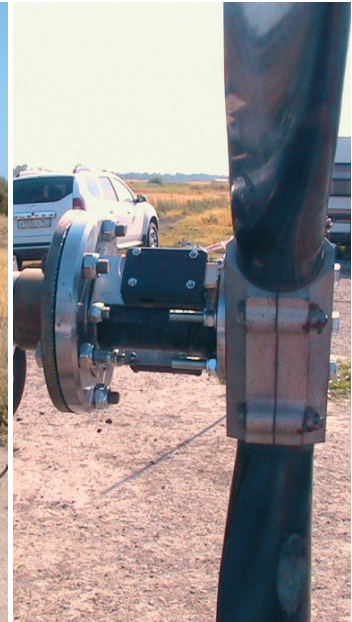

(b)
Fig. 3. Test bench for measuring the characteristics of aviationused engines (a) and the torque meter installed on intermediate shaft (b) (Source: Author's own figure).

\section{Research methodology}

The bench tests aim to detect the changes of engine unit performance caused by the motor oil modification. The tests assumed two step measurements:

1) engine with initial motor oil;

2) engine with modified motor oil after 2 hours of operation.

The tests were performed by increasing the rotation frequency to its maximum possible value at the current blade pitch angle of the propeller. The step of blade pitch angle change was $3^{\circ}$. The zero blade pitch angle corresponds to the minimum angle of operating range and the maximum value was $15^{\circ}$.

The Komol additive was injected after the tests with the initial oil within the operating range of the blade pitch angles. After two hours of idle engine operation the tests were repeated for the same range of blade pitch angles.

Fig. 4 demonstrates an example record of the engine torque value. It is clear that in the case of four-stroke engine the values of torque are strongly nonlinear during the recording time and should be time-averaged.

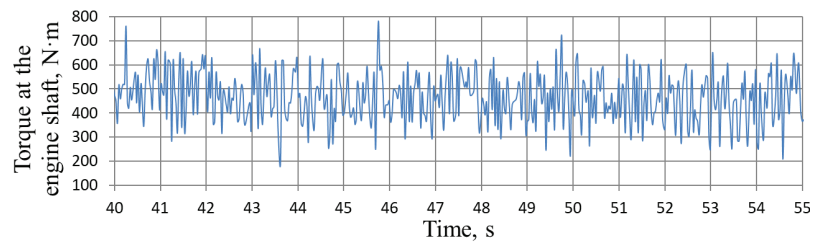

Fig. 4. An example record of the torque value at the engine shaft after 2 hours of operation with modified motor oil at blades pitch angle of $0^{\circ}$.

\section{Measurement results}

The bench test results demonstrate a general tendency for increasing the values of torque and maximum rotation frequency after the motor oil modification. Thus the engine power increased when the modified motor oil was used.

After 2-hour operation with modified motor oil, the observed average values of rotation frequency increased by $4,1 \%$, torque $-6,4 \%$ and the power $-10,7 \%$. The effect was observed for the full operating range of the blades pitch angles (Table 2).

The engine power and torque depending on rotation frequency and the propeller blades pitch angle are shown in Fig. 5-7.

Table 2. The results of bench tests of the engine motor oil in the initial state and after 2-hour operation with Komol additive.

\begin{tabular}{|c|c|c|c|c|c|c|c|c|}
\hline 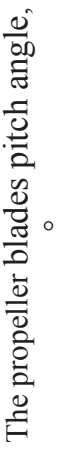 & 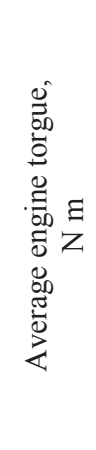 & 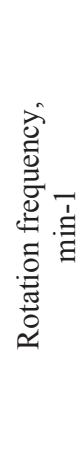 & $\begin{array}{l}\dot{\vec{D}} \dot{2} \\
\dot{0} \dot{0}\end{array}$ & 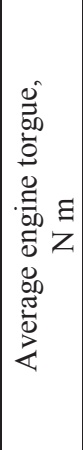 & 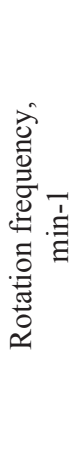 & 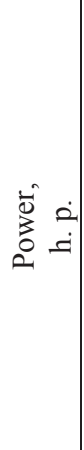 & 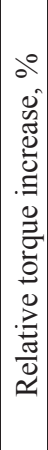 & 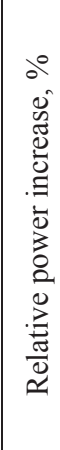 \\
\hline 15 & 195,3 & 4800 & 133,3 & 181,3 & 4617 & 119,0 & 7,7 & 12,0 \\
\hline 12 & 187,4 & 5260 & 140,2 & 176,6 & 5020 & 126,1 & 6,1 & 11,2 \\
\hline 9 & 178,6 & 5660 & 143,8 & 168,3 & 5390 & 129,0 & 6,1 & 11,4 \\
\hline 6 & 167,7 & 6095 & 145,4 & 156,8 & 5900 & 131,6 & 7,0 & 10,5 \\
\hline 3 & 152,3 & 6660 & 144,2 & 144,2 & 6450 & 132,3 & 5,6 & 9,1 \\
\hline 0 & 140,0 & 7295 & 145,2 & 132,3 & 7000 & 131,7 & 5,8 & 10,3 \\
\hline & \multirow{2}{*}{\multicolumn{3}{|c|}{$\begin{array}{c}\text { Modified oil } \\
\text { (2-hours operating time) }\end{array}$}} & \multirow{2}{*}{\multicolumn{3}{|c|}{ Initial oil }} & \multicolumn{2}{|c|}{ Total } \\
\hline & & & & & & & 6,4 & 10,7 \\
\hline
\end{tabular}

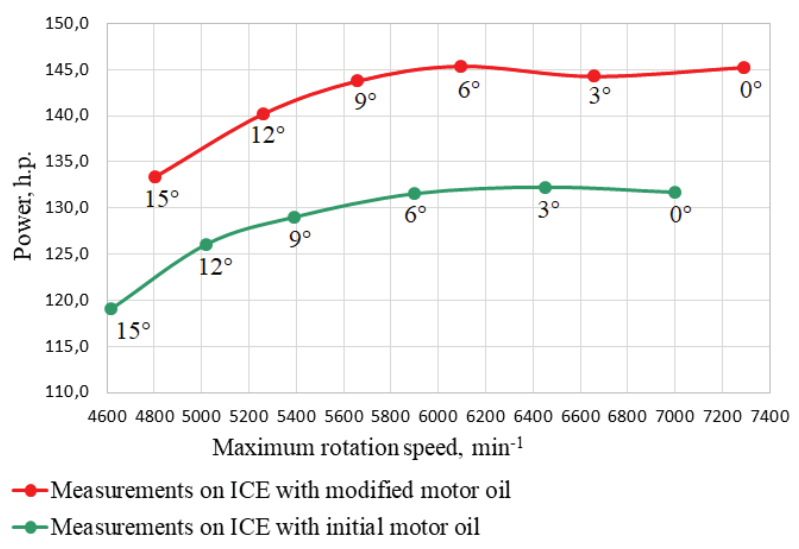

Fig. 5. The ICE power depending on the maximum rotation frequency at the various propeller blades pitch angle for the conditions of initial motor oil and after 2-hour operation with modified one. 


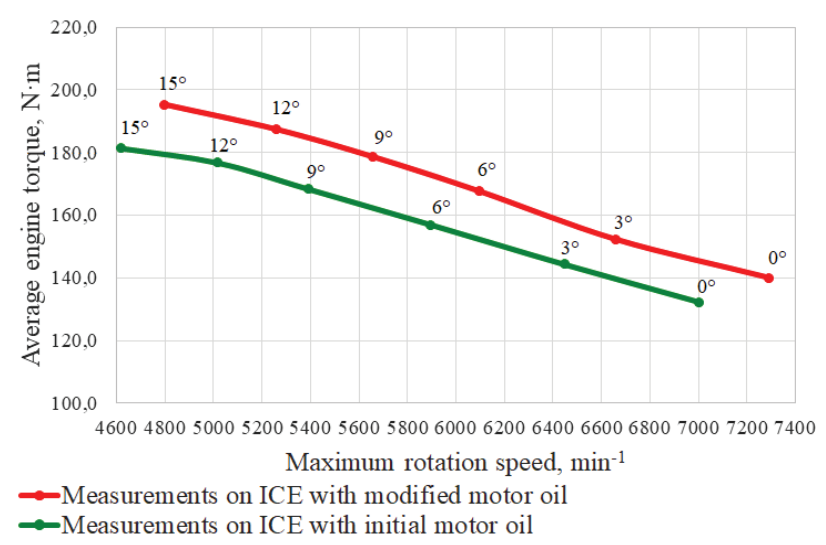

Fig. 6. The torque on ICE shaft dependence on the maximum rotation frequency at various propeller blades pitch angle for the conditions of initial motor oil and after 2-hour operation with modified oil.

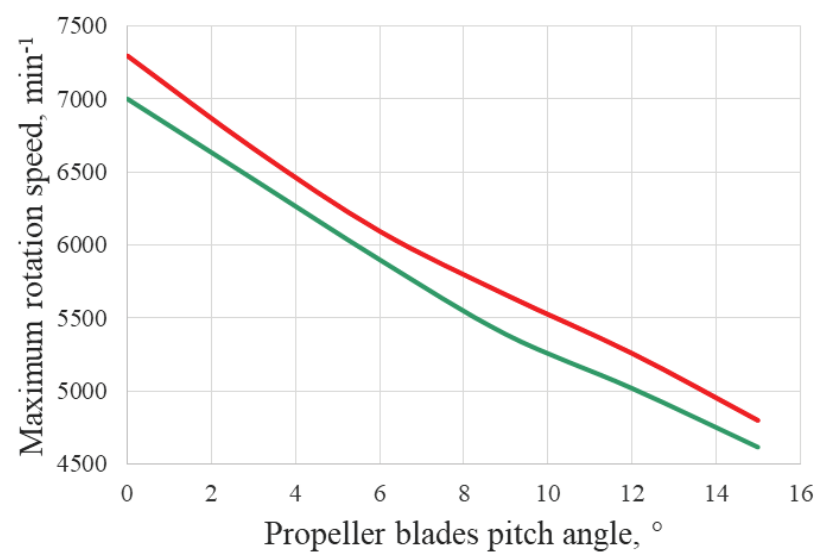

-Measurements on ICE with modified motor oil - Measurements on ICE with initial motor oil

Fig. 7. Maximum rotation frequency dependence on the propeller blades pitch angle for the conditions of initial motor oil and after 2 hours of operation with modified oil.

The results of the measurements show that despite the increase in the engine rotation frequency the power almost stops to grow. The real power on the engine shaft was higher due to losses occuring in one-step reduction gear. However, these losses were negligible and do not influence the relative value of power increase.

Finally, the approximate functions that describe the relation between the maximal power of the engine and the rotation frequency have been obtained. Thus, in the case of initial oil the following equation is obtained:

$$
\begin{aligned}
P= & 1,573 \times 10^{-9} \omega^{3}-31604,555 \times 10^{-9} \omega^{2}+ \\
& +211000989,904 \times 10^{-9} \omega-336,103
\end{aligned}
$$

where:

$P$ - engine power, h. p.;

$\omega$ - maximum engine rotation frequency, $\mathrm{min}^{-1}$.

For the case of modified oil:

$$
\begin{aligned}
P= & 2,404 \times 10^{-9} \omega^{3}-47252,830 \times 10^{-9} \omega^{2}+ \\
& +308814304,368 \times 10^{-9} \omega-526,303
\end{aligned}
$$

The obtained approximation functions allow us to find out the engine power at comparable rotation speeds. The increase in power at the same rotational speeds is

\begin{tabular}{|c|c|c|c|c|}
\hline \multirow{2}{*}{ 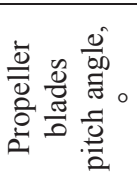 } & \multirow{2}{*}{ 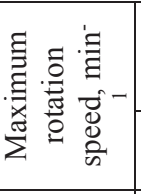 } & Initial oil & $\begin{array}{c}\text { Modified oil } \\
\text { (2-hours } \\
\text { operating) }\end{array}$ & \multirow{2}{*}{ 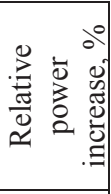 } \\
\hline & & $\begin{array}{c}\text { Engine } \\
\text { power, h. p. }\end{array}$ & $\begin{array}{c}\text { Engine } \\
\text { power, h. p. }\end{array}$ & \\
\hline 15 & 4800 & 122,494 & 133,164 & 8,0 \\
\hline 12 & 5200 & 127,691 & 139,8364 & 8,7 \\
\hline 9 & 5600 & 130,628 & 143,3894 & 8,9 \\
\hline 6 & 6000 & 131,907 & 144,745 & 8,9 \\
\hline 3 & 6400 & 132,133 & 144,827 & 8,8 \\
\hline 0 & 6800 & 131,911 & 144,558 & 8,7 \\
\hline \multicolumn{4}{|c|}{ Total: } & 8,7 \\
\hline
\end{tabular}
$8,7 \%$.

Table 3. Engine power variation at comparable rotation speeds.

\section{Conclusion}

The results of comparative tribometric tests of additives concentrates with coordination compounds of different transition metals in SAE10W40 motor oil demonstrate that injected additives reduce the value of friction coefficient by the rate of 4,9-8,3. This effect can be explained by the antifriction tribopolymer film formed on friction surfaces.

The most effective one is the concentrate additive Komol containing a complex of molybdenum.

The results of propeller engine unit bench tests demonstrate that motor oil modification by the additive compound Komol increases produced power by $8,7 \%$ at comparable rotation speeds.

The proposed technology can be used in gasoline and diesel internal combustion engines in road, rail and other modes of transport.

This work was supported by the Ministry of Education and Sciences of the Russian Federation (project no. 14.575.21.0095). Unique identifier of applied scientific research (project) RFMEFI57514X0095.

\section{References}

1. G. Colas, A. Saulot, C. Godeau, Y. Michel, Y. Berthier, Wear 305, 192-204 (2013)

2. N. Gosvami, J. Bares, F. Mangolini, A. Konicek, D. Yablon, R. Carpick, Science 348, 102-106 (2015)

3. M. Nicholls, T. Dob, P. Norton, M. Kasrai, G. Bancroft, Tribology International 38, 15-39 (2005)

4. A. Ponomarenko, A. Burlov, M. Boiko, T. Shiryaeva, A. Kalmykova, S. Zaichenko, M. Milutka, Journal of Friction and Wear 36-1, 15-22 (2015)

5. A. Ponomarenko, M. Boiko, A. Burlov, A. Kalmykova, T. Bozhenko, Tribochemical nanotechnology for energy-saving lubricants, SGEM 2015 Proceedings, 235-242 (2015). 